10. Koukila-Kähkölä P, Paulin L, Brander E, Jantzen E, Eho-Remes M, Katila ML. Characterisation of a new isolate of Mycobacterium shimoidei from Finland. J Med Microbiol. 2000;49:937-40. http://dx.doi.org/10.1099/0022-1317-49-10-937

Address for correspondence: Timothy M. Baird, Metro South Clinical Tuberculosis Service and Respiratory and Sleep Medicine Department, Princess Alexandra Hospital, Queensland Health, 199 Ipswich Rd, Wooloongabba, Queensland, 4102 Australia; email: tmbaird@gmail.com

\section{The Breadth of Viruses in Human Semen}

\author{
Alex P. Salam, Peter W. Horby \\ Author affiliation: University of Oxford, Oxford, UK
}

DOI: https://doi.org/10.3201/eid2311.171049

Zika virus RNA is frequently detected in the semen of men after Zika virus infection. To learn more about persistence of viruses in genital fluids, we searched PubMed for relevant articles. We found evidence that 27 viruses, across a broad range of virus families, can be found in human semen.

$\mathrm{T}$ he finding by Atkinson et al. that Zika virus RNA is frequently detected in the semen of men after infection (1) highlights our knowledge gaps regarding the persistence of viruses in genital fluids, especially semen. Replicating Zika virus (2), like Ebola and Marburg viruses (3), has been isolated from semen and has been sexually transmitted. However, it is probable that many more viruses capable of causing viremia (presence of virus in the blood) can be found in semen. Seeding to the male reproductive tract may frequently occur in the context of viremia because the bloodtestes/deferens/epididymis barriers are imperfect barriers to viruses, especially in the presence of systemic or local inflammation (4). Virus may persist even if incapable of replicating within the male reproductive tract because the testes are immunologically privileged (4); that is, within the testes, the immune response is restricted to enable the survival of sperm, which are immunogenic. Virus may also be transmitted to semen as a result of survival and replication within the accessory glands (5).

To investigate the breadth of viruses in semen, we performed a PubMed search by using the terms "virus* AND semen OR sperm* OR seminal." We imposed no date or language restrictions. This search returned 3,818 results. We screened the titles, abstracts, and full text articles for data that described detection of viruses in semen by nucleic acid amplification or detection, antigen detection, replication in cell culture, or replication in an animal system. We restricted the results to viruses capable of causing viremia. Where we found evidence for virus in semen, we then searched PubMed for evidence of sexual transmission by using the terms "(name of virus) AND sex* AND Transm*."

Our search revealed that 27 viruses that can result in viremia have been found in human semen (Table). For many of these, data on sexual transmission are lacking. Of these 27 viruses, many cause chronic or latent infection (e.g., HIV virus, cytomegalovirus). However, several cause acute infections, including Lassa fever, Rift Valley fever, and chikungunya viruses. Of those causing acute infections, only Zika and Ebola viruses have been systematically screened for in semen (i.e., in case series or cohort studies rather than case reports). These 27 viruses come from diverse families, suggesting that the presence of many viruses in semen is unlikely to be exclusively dependent on specific or conserved viral epitopes, ability of virus to replicate within the male reproductive tract, or common mechanisms of immune evasion. Other factors that may also influence whether viruses exist in semen are level of viremia, inflammatory mediators (altering bloodbarrier permeability), systemic immunosuppression, male reproductive tract immune responses, presence of sexually transmitted diseases, and virus structural stability. In mammals, numerous viruses are detectable in semen, including viruses that can cause disease in humans, such as Japanese encephalitis virus, foot and mouth disease virus, parainfluenza virus, and paravaccinia virus (6). Several other viruses that result in viremia can cause orchitis and have been detected in human testes, suggesting the possibility that these viruses may also be detectable in semen. These viruses include influenza virus, lymphocytic choriomeningitis virus, phlebotomus fever virus, cocksackie B virus, echovirus, dengue virus, systemic acute respiratory syndrome virus, parvovirus, smallpox virus, vaccinia virus, and rubella virus (7).

Given these findings, the following questions need to be addressed: which viruses are shed and remain viable in semen, for how long, and at what concentrations? The answers to these questions have implications for risks for sexual transmission and, therefore, embryonic infection, congenital disease, miscarriage, and effects on epidemiologic and transmission models. The presence of virus in the male reproductive tract may increase the risk for acquisition of sexually transmitted infections and may reduce male fertility through spermatogonial stem cell infection or local inflammation. Infection of spermatozoa could result in transmission of virus-induced mutations to subsequent 
Table. Viruses that are capable of causing viremia and found in human semen*

\begin{tabular}{|c|c|c|c|c|}
\hline Virus & Family & $\begin{array}{c}\text { Detection in } \\
\text { semen, maximum } \\
\text { detection time, } d\end{array}$ & $\begin{array}{c}\text { Isolation from } \\
\text { semen, maximum } \\
\text { detection time, } d\end{array}$ & $\begin{array}{c}\text { Evidence for } \\
\text { sexual transmission } \\
\text { within same cohort }\end{array}$ \\
\hline Adenoviruses & Adenoviridae & $\mathrm{AD}$ & RCC & Unknown \\
\hline Transfusion transmitted virus & Anelloviridae & NAA & No data found & Unknown \\
\hline Lassa fever virus $\dagger$ & Arenaviridae & NAA, 103 & RCC, 20 & Unknown \\
\hline Rift Valley fever virus $†$ & Bunyaviridae & NAA, 117 & No data found & Unknown \\
\hline Ebola virus & Filoviridae & NAA, 531 & $\mathrm{RCC}, 82$ & $\mathrm{Epi}+\mathrm{mol}+\mathrm{sem}$ \\
\hline Marburg virus $\dagger$ & Filoviridae & $A D, 83$ & RAS, 83 & Epi + sem \\
\hline GB virus $\mathrm{C}$ & Flaviviridae & NAA & No data found & Epi + mol \\
\hline Hepatitis C virus & Flaviviridae & NAA; AD & No data found & Epi + mol \\
\hline Zika virus & Flaviviridae & NAA, 188 & $\mathrm{RCC}, 7$ & $\mathrm{Epi}+\mathrm{mol}+\mathrm{sem}$ \\
\hline Hepatitis B virus & Hepadnaviridae & NAA; AD & RAS & Epi + mol \\
\hline Cytomegalovirus & Herpesviridae & NAA & $\mathrm{RCC}$ & $\mathrm{Epi}+\mathrm{mol}+\mathrm{sem}$ \\
\hline Epstein Barr virus & Herpesviridae & NAA & No data found & Epi and semen \\
\hline Human herpes virus 8 & Herpesviridae & NAA & $\mathrm{RCC}$ & Epi + mol \\
\hline Human herpes virus 7 & Herpesviridae & NAA & No data found & Unknown \\
\hline Human herpes virus 6 & Herpesviridae & NAA & No data found & Unknown \\
\hline Human simplex viruses 1 and 2 & Herpesviridae & NAA; AD & RCC & $\mathrm{Epi}+\mathrm{mol}+\mathrm{sem}$ \\
\hline Varicella zoster virus & Herpesviridae & NAA & No data found & Unknown \\
\hline Mumps virus $\dagger$ & Paramyxoviridae & NAA, 40 & RCC, 14 & Unknown \\
\hline Adeno-associated virus & Parvoviridae & NAA & RCC & Unknown \\
\hline BK virus & Polyomaviridae & NAA & No data found & Unknown \\
\hline $\mathrm{JC}$ virus & Polyomaviridae & NAA & No data found & Unknown \\
\hline Simian virus 40 & Polyomaviridae & NAA & No data found & Unknown \\
\hline HIV & Retroviridae & $\mathrm{NAA} ; \mathrm{AD}$ & RCC & $\mathrm{Epi}+\mathrm{mol}+\mathrm{sem}$ \\
\hline Human T-cell lymphoma virus $1 \dagger$ & Retroviridae & No data found & RAS & Epi + mol \\
\hline Simian foamy virus & Retroviridae & NAA & No data found & Unknown \\
\hline Chikungunya virust & Togaviridae & NAA, 30 & No data found & Unknown \\
\hline \multicolumn{5}{|c|}{$\begin{array}{l}\text { *Presence of nucleic acid or antigen in semen does not represent the presence of replication-competent or infection-competent virus, which can generall } \\
\text { only be demonstrated by isolation and culture of virus. Maximum detection time refers to time from symptom onset (only in viruses that cause acute only, } \\
\text { not chronic, infection). A complete table with references is provided in the online Technical Appendix (https://wwwnc.cdc.gov/EID/article/23/11/17-1049- } \\
\text { Techapp1.pdf). AD, antigen detection; Epi, epidemiologic evidence of sexual transmission; mol, molecular/phylogenetic evidence of sexual transmission; } \\
\text { NAA, nucleic acid amplification or detection; RAS, replication in animal system; RCC, replication in cell culture; sem, isolation from semen. } \\
\text { †Data found only in the context of case reports and not case series, case control, or cohort studies. }\end{array}$} \\
\hline
\end{tabular}

generations, thereby elevating risks for cancer and other disorders. Indeed, when virus has been detected in human semen, the extent to which virus existence and replication occurs within spermatozoa is unclear $(8)$. Not all therapeutics will cross the male reproductive tract-blood barriers, and viruses may persist in semen despite systemic clearance of virus, highlighting the need to consider the male reproductive tract-blood barriers when choosing therapeutic agents in clinical trials. Virus within the male reproductive tract can also be genetically distinct from virus in other compartments, including blood (9), which has implications for gene-based vaccines and therapeutics.

The presence of viruses in semen is probably more widespread than currently appreciated, and the absence of virus in genital secretions should not be assumed for traditionally non-sexually transmitted viruses. The investigation of virus detection and persistence in semen across a range of viruses is useful for clinical and public health reasons, in particular for viruses that lead to high mortality or morbidity rates or to epidemics.

Dr. Salam is a clinician and clinical researcher for the United Kingdom Public Health Rapid Support Team. His research interests are clinical trials in epidemic diseases.
Dr. Horby is Professor of Emerging Infectious Diseases and Global Health at the University of Oxford. His research is focused on improving the clinical and public health response to emerging and epidemic-prone infectious diseases in high- and low-income settings.

\section{References}

1 Atkinson B, Thorburn F, Petridou C, Bailey D, Hewson R, Simpson AJH, et al. Presence and persistence of Zika virus RNA in semen, United Kingdom, 2016. Emerg Infect Dis. 2017;23:611-5. http://dx.doi.org/10.3201/eid2304.161692

2. Moreira J, Peixoto TM, Siqueira AM, Lamas CC. Sexually acquired Zika virus: a systematic review. Clin Microbiol Infect. 2017;23:296-305. http://dx.doi.org/10.1016/j.cmi.2016.12.027

3. Brainard J, Pond K, Hooper L, Edmunds K, Hunter P. Presence and persistence of Ebola or Marburg virus in patients and survivors: a rapid systematic review. PLoS Negl Trop Dis. 2016;10:e000447517. http://dx.doi.org/10.1371/journal.pntd.0004475

4. Li N, Wang T, Han D. Structural, cellular and molecular aspects of immune privilege in the testis. Front Immunol. 2012;3:152. http://dx.doi.org/10.3389/fimmu.2012.00152

5. Hirsch AJ, Smith JL, Haese NN, Broeckel RM, Parkins CJ, Kreklywich C, et al. Zika virus infection of rhesus macaques leads to viral persistence in multiple tissues. PLoS Pathog. 2017; 13:e1006219-23. http://dx.doi.org/10.1371/journal.ppat.1006219

6. Kahrs RF, Gibbs EP, Larsen RE. The search for viruses in bovine semen, a review. Theriogenology. 1980;14:151-65. http://dx.doi.org/10.1016/0093-691X(80)90101-6 
7. Dejucq N, Jégou B. Viruses in the mammalian male genital tract and their effects on the reproductive system. Microbiol mol Biol Rev. 2001;65:208-31. http://dx.doi.org/10.1128/ MMBR.65.2.208-231.2001

8. Mansuy JM, Suberbielle E, Chapuy-Regaud S, Mengelle C, Bujan L, Marchou B, et al. Zika virus in semen and spermatozoa. Lancet Infect Dis. 2016;16:1106-7. http://dx.doi.org/10.1016/ S1473-3099(16)30336-X

9. Pillai SK, Good B, Pond SK, Wong JK, Strain MC, Richman DD, et al. Semen-specific genetic characteristics of human immunodeficiency virus type 1 env. J Virol. 2005;79:1734-42. http://dx.doi.org/10.1128/JVI.79.3.1734-1742.2005

Address for correspondence: Alex Paddy Salam, Epidemic Diseases Research Group, University of Oxford, Wellcome Trust Centre for Human Genetics, Roosevelt Drive, Oxford OX3 7BN, UK; email: alexsalam@doctors.org.uk

\section{Legionella pneumophila Serogroup 1 in the Water Facilitites of a Tertiary Healthcare Center, India}

\section{Rama Chaudhry, K. Sreenath, Valavane Arvind, E.V. Vinayaraj, Sagar Tanu}

Author affiliation: All India Institute of Medical Sciences,

New Delhi, India

DOI: https://doi.org/10.3201/eid2311.171071

Proactive environmental surveillance for Legionella pneumophila in hospitals that treat immunocompromised patients is a useful strategy for preventing nosocomial Legionnaires' disease. We report the presence of $L$. pneumophila serogroup 1 in $15.2 \%$ of the water systems of our tertiary healthcare center, which should prompt health officials to formulate mitigation policies.

$L$ egionella pneumophila, the causative agent of Legionnaires' disease (LD), is a bacterium omnipresent in aquatic environments and increasingly recognized as a major cause of community- and hospital-acquired pneumonia. L. pneumophila serogroup 1 ( $L p 1)$, the dominant serogroup, accounts for $\approx 84 \%$ of human infections worldwide $(1,2)$. Hospital-acquired LD has been reported globally, and routine use of environmental cultures is recommended as a useful strategy to prevent infections (3). Although proactive environmental surveillance of Legionella and regular treatment of cooling tower installations are recommended in many countries, these practices are not routine in India, and limited studies have been conducted in this country for monitoring Legionella contamination in hospital water systems (4). We conducted a study to detect L. pneumophila and to identify $L p 1$ in the water systems of a tertiary healthcare center in northern India that has organ transplantation and cancer treatment facilities.

We collected 79 water samples (41 potable, 38 nonpotable) from the hospital and general areas of the healthcare center during an 18-month period (May 2015-October 2016). Of 79 samples, 27 were collected from patient areas (wards, intensive care units, outpatient departments, emergency units, and procedure rooms); 14 from residential areas; 15 from cooling towers; and 23 from other buildings (e.g., laboratory divisions, teaching departments, library, and recreational zones). We followed guidelines issued by the US Centers for Disease Control and Prevention regarding isolation of Legionella (5). In brief, we concentrated $500 \mathrm{~mL}$ of water samples and decontaminated 1 part by using heat treatment (in water bath at $50^{\circ} \mathrm{C}$ for $30 \mathrm{~min}$ ) and 1 part by acid (in equal volume of $\mathrm{HCl}-\mathrm{KCl}$ acid buffer [ $\mathrm{pH}$ 2.2]). We then inoculated 0.1-mL samples onto buffered charcoal yeast extract agar (Becton Dickinson, Sparks, MD, USA) supplemented with glycine, vancomycin, polymyxin B, and cycloheximide (Oxoid, Basingstoke, UK). We presumptively identified colonies growing only on buffered charcoal yeast extract but not on blood agar as Legionella species and confirmed the presence of L. pneumophila by amplification of a 375-bp region of the mip gene using previously published primers (6). We identified $L p 1$ by using a real-time PCR (rPCR) assay targeting the wzm gene (7). We used genomic DNA isolated from $L$. pneumophila strain Philadelphia (ATCC 33152) for standardization of PCR and rPCR and L. pneumophila strain Knoxville (ATCC 33153) for standardization of culture.

We identified Legionella spp. in 21 (26.6\%) of 79 water samples (10 potable and 11 nonpotable) by culture. We obtained a collection of 28 isolates from the 79 samples and identified all of them as L. pneumophila by PCR. Among these 28 isolates, 18 (64.3\%) tested positive for $L p 1$ by $\mathrm{rPCR}$, indicating the presence of this pathogenic serogroup in $12(15.2 \%)$ of the 79 water samples (5 potable and 7 nonpotable).

We repeatedly isolated L. pneumophila ( $>4$ times) from 2 high-risk sites: a drinking water unit and a cooling tower situated inside the hospital campus. Four water samples collected from patient areas tested positive for L. pneumophila, posing a risk for nosocomial infection. We isolated L. pneumophila from water bodies with temperatures ranging from $12^{\circ} \mathrm{C}$ to $57^{\circ} \mathrm{C}$ but most frequently (11 times) from those with temperatures of $25^{\circ} \mathrm{C}-50^{\circ} \mathrm{C}$. We summarized the isolation of $L$. pneumophila with 